\title{
PROBLEMAS MATEMÁTICOS NA VIDA COTIDIANA
}

\author{
Lívia Cuartero Gimenes ${ }^{1}$ \\ Adriana Meroni ${ }^{2}$ \\ Adriana Varani ${ }^{3}$
}

Durante o segundo semestre do ano de dois mil e quinze, cumprimos o estágio obrigatório da disciplina Estágio Supervisionado II - Anos iniciais do Ensino Fundamental, sob a supervisão da Professora Adriana Varani. Esta disciplina é pertencente à grade obrigatória do curso de Pedagogia pela Universidade Estadual de Campinas- UNICAMP, sendo necessário o cumprimento de sessenta horas dentro de sala de aula em classe do ensino fundamental.

O estágio foi cumprido na escola EMEF Dulce Bento Nascimento, localizada no bairro Guará, em Campinas-SP, junto com a turma do quinto ano B, sob a supervisão da Professora Adriana Meroni, responsável pela turma. A partir do conceito de ser um estágio supervisionado, foram necessários dois direcionamentos principais para o cumprimento do mesmo. $\mathrm{O}$ primeiro consistia em vivência e reconhecimento da turma na qual iríamos estagiar. O segundo consistia que a partir deste reconhecimento teríamos que junto com a professora da sala e turma elaborar um projeto de atuação que, de alguma forma, implicasse em promover uma educação que demonstrasse a potência da criança na escola para além de sua dimensão cognitiva, que fosse em busca de uma formação humana mais ampliada. Esta proposta de estágio visava ressaltar a importância da construção conjunta de saberes, em que o aluno estagiário e os educadores da escola se "comunicam" a respeito do "objeto cognoscível", se comunicam a respeito da criança, refletem juntos sobre os determinantes da realidade que os circunda, elaboram em conjunto conhecimentos, e atuam sobre as circunstâncias com objetivo de transformá-las (FREIRE, 1983).

Partindo da vivência com a turma percebemos uma grande dificuldade na resolução e interpretação de problemas matemáticos por parte de vários estudantes. Foi então solicitado pela professora que o projeto de atuação fosse sobre resolução de problemas matemáticos. Concomitantemente ao curso da disciplina de estágio, estava cursando a disciplina Escola e cultura matemática, o que facilitou na proposta de elaboração do projeto de atuação.

Portanto, o projeto justificava-se na dificuldade que a turma possuía na realização de problemas matemáticos. Segundo o material Pacto Nacional pela Alfabetização na Idade CertaPNAIC, no caderno que trata especificadamente sobre Operações na Resolução de Problemas, encontra-se a seguinte definição:

Uma proposta pedagógica pautada na Resolução de Problemas possibilita que
as crianças estabeleçam diferentes tipos de relações entre objetos, ações e
eventos a partir do modo de pensar de cada uma, momento em que
estabelecem lógicas próprias que devem ser valorizadas pelos professores. A
partir delas, os alunos podem significar os procedimentos da resolução e
construir ou consolidar conceitos matemáticos pertinentes às soluções.
(BRASIL, 2014, p. 8)

Assim, o projeto de atuação deveria unir a resolução de problemas matemáticos com a vida cotidiana das crianças, tendo como objetivo a percepção que solucionamos problemas

\footnotetext{
${ }^{1}$ Universidade Estadual de Campinas.

${ }^{2}$ Prefeitura Municipal de Paulínia - Secretaria de Educação; Prefeitura Municipal de Campinas - Secretaria de Educação.

${ }^{3}$ Universidade Estadual de Campinas.
} 
matemáticos diariamente e também correlacionar à resolução de problemas matemáticos com a leitura e interpretação de texto. Para a realização deste projeto, foi necessária a utilização de cinco encontros, com um período de duas horas cada um.

Vamos focalizar a reflexão em algumas das atividades promovidas. A primeira atividade a ser retomada foi realizada no segundo dia de trabalho como estagiária, junto com a professora. A atividade consistia em uma roda de conversa com os alunos visando a seguinte pergunta: onde podemos encontrar a matemática no dia-a-dia? As respostas foram: escola, compras, vendas, número de casas, placas de carros, relógios, placas de velocidade, controle e administração do tempo, calculadora e tecnologia. A partir daí os alunos registraram suas falas em cartazes.

A segunda proposta de atividade retomava a roda de conversa. Foram levadas imagens a partir do que os alunos disseram, por exemplo: jogos, mercado, etc. O objetivo foi que em pares construíssem seus próprios problemas matemáticos, criando quatro problemas que envolvessem cada uma das operações matemáticas (adição, subtração, divisão e multiplicação). Ao final, os problemas, foram trocados pelas duplas, para que a turma tivesse a oportunidade de solucionálos. Esta atividade foi a que mais surpreendeu, pois apareceram problemas de grande complexidade, como por exemplo:

Uma escola tinha $\mathrm{R} \$ 9800,00$. Comprou 3 bebedouros de $\mathrm{R} \$ 2600,00$. Um bebedouro quebrou, e a escola recebeu o dinheiro de volta. Depois que devolveram o dinheiro, compraram um bebedouro simples de R $\$ 1800,00$. Quanto dinheiro sobrou? (GIMENES, 2015, p. 18)

Refletimos que este tipo de proposta de criação de problemas ajuda-os a compreender que cada problema tem uma intenção e uma estratégia a ser utilizada na sua resolução. Seguindo etapas de leitura e interpretação dos problemas os alunos conseguem resolvê-los, o que constatamos na troca. Todos os problemas foram resolvidos pelos alunos, mesmo que alguns com mediação.

Interessante notar o quanto a criança estabeleceu um problema que poderia estar diretamente relacionado às suas vivências no interior da escola, o que mostra a dimensão da criança enquanto ser social, enquanto sujeito que pode se posicionar no mundo, inclusive, pela condução de resolução de problemas. Esta é uma dimensão que, se considerada na organização do trabalho pedagógico, a criança pode sentir que o conhecimento determinado como objeto de estudo tem relevância social.

A terceira proposta de atividade foi à elaboração de um "mercadinho", na qual os alunos trouxeram sucatas para sua montagem. A partir dos itens que eles trouxeram, foi elaborado perguntas em três níveis: um, dois e três. Conforme, as duplas terminavam os problemas de cada nível avançavam para outro. Até conseguirem resolver o nível difícil. Seu objetivo era estimular a interpretação de problemas que antes resolviam com muita dificuldade. Na atividade os preços dos itens estavam tabelados, então além de interpretar os problemas, eles também teriam que interpretar tabela.

Como exemplo de pergunta do nível um:

Tenho $\mathrm{R} \$ 50,00$. Preciso comprar no mercado 1 amaciante de roupas, 2 garrafas de refrigerante, 1 garrafa de azeite, 1 lata de pêssego. Vou conseguir comprar com o dinheiro que eu tenho? Vai sobrar troco? Quanto? (GIMENES, 2015, p. 24)

Nível dois:

Para uma visita ao museu, uma escola precisou comprar para os alunos 100 caixas de suco individual, 20 pacotes de bisnaguinha, $5 \mathrm{~kg}$ de presunto fatiado 
e $5 \mathrm{~kg}$ de queijo fatiado. Qual será o total da compra sabendo que paguei R\$ 17,00 pelo quilo do presunto e $\mathrm{R} \$ 15,00$ pelo quilo do queijo? (GIMENES, 2015, p. 25)

Nível três:

Luiz é dono de um asilo. Rafael que é o dono do mercado tem o seguinte acordo com o Luiz: A cada 200 reais que o mercado fatura, é doado para o asilo 1 sabonete. Quantos sabonetes o asilo do Luís ganhará este mês se o mercado faturou $\mathrm{R} \$ 50.000,00$ reais este mês? (GIMENES, 2015, p. 25 e 26)

Os problemas mudavam de complexidade, aumentando as operações, raciocínio e quantidades.

Este projeto foi pensado a partir de uma linha de continuidade, partindo de princípios matemáticos básicos, para raciocínios exigidos numa turma de quinto ano. Um dos desafios foi que, na turma, havia um menino que possuía uma deficiência que comprometia seu desenvolvimento cognitivo. Ele foi inserido no projeto participando dos grupos, e desenvolvendo junto com a turma suas capacidades artísticas e de contagem das primeiras dezenas.

Diante das situações vividas no campo do estágio e apresentadas aqui, podemos afirmar que, em processo de colaboração com a professora da turma em que ocorre o estágio e no diálogo com a universidade sob a orientação do professor no processo de formação, pudemos elaborar algumas sínteses sobre o vivido. O primeiro é a importância deste diálogo entre os vários sujeitos e instituições envolvidas: aluno estagiário, orientador da universidade, professora da escola e crianças. O estágio não pode se restringir à ida a escola e observação, temos que viver a vida que ocorre ali. Uma segunda questão é o quanto o trabalho pedagógico pode ser mais significativo quando as crianças estão envolvidas nas atividades. Foi o percebido pelo feedback dado pelos alunos no projeto. Tendo em vista o avanço das crianças nas atividades, as respostas recebidas, acreditamos que seu resultado tenha sido satisfatório. A elaboração de atividades lúdicas e participativas ajudou para o envolvimento da turma, que realizava as atividades com empolgação.

\section{Referências}

BRASIL. Ministério de Educação. Pacto Nacional pela Alfabetização na Idade Certa. Construção do sistema de numeração decimal. Disponível em: <http://pacto.mec.gov.br/2012-09-19-19-0911>. Acesso em: 04/10/2015.

. Ministério de Educação. Pacto Nacional pela Alfabetização na Idade Certa. Operações na resolução de problemas. Disponível em: 〈http://pacto.mec.gov.br/2012-09-19-19-09-11〉. Acesso em: 04/10/2015.

Ministério de Educação. Pacto Nacional pela Alfabetização na Idade Certa. Educação matemática inclusiva. Disponível em: 〈http://pacto.mec.gov.br/2012-09-19-19-09-11〉. Acesso em: 04/10/2015.

Ministério de Educação. Pacto Nacional pela Alfabetização na Idade Certa. Jogos na alfabetização matemática. Disponível em: 〈http://pacto.mec.gov.br/2012-09-19-19-09-11〉. Acesso em: 04/10/2015. 
FREIRE, P.; OLIVEIRA, R. D. Extensão ou comunicação? 12. ed. Rio de Janeiro, RJ: Paz e Terra, c2002. p. 93.

GIMENES, L. Diário de Campo 4. In: I Seminário Experiência em Estágio Docente, VI Encontro e II Mostra do PIBID-Unicamp e XII Encontro de Estudantes de Graduação dos Cursos de Formação de Professores da Unicamp, 2015. Campinas- SP. Diários de Campo. Universidade Estadual de Campinas - Unicamp, Faculdade de Educação, p. 18-26.

\section{Sobre as autoras}

Lívia Cuartero Gimenes é graduanda do quarto ano noturno do curso de Pedagogia pela Universidade Estadual de Campinas- UNICAMP.

E-mail: liviacgimenes@hotmail.com.

Adriana Ignácio de Campos Meroni é pedagoga, professora da rede municipal de Campinas e diretora da rede municipal de Paulínia.

E-mail: meroni.adriana@gmail.com.

Adriana Varani é pedagoga, professora doutora da FE/UNICAMP e orientadora de estágio. E-mail: drvarani@unicamp.br. 